\title{
Field Testing of Flipbook on Hygiene During Menstruation for its Comprehension by Rural Women
}

\author{
Seema Dangi and Vishakha Bansal* \\ Department of Extension Education and Communication Management, \\ CH. Sc., MPUAT, Udaipur, Rajasthan, India \\ *Corresponding author
}

\section{A B S T R A C T}

\begin{tabular}{|l|}
\hline Ke y w o r d s \\
Hygiene, \\
Menstruation and \\
Field testing
\end{tabular}

\section{Keywords}

Hygiene,

Menstruation and

ield testing

cle Info

08 June 2018

10 July 2018
The study was conducted in randomly selected Girwapanchayatsamiti of Udaipur district of Rajasthan state with a sample of 50 rural women to field test flipbook for its comprehension by rural women. Findings revealed that Overall comprehension of flipbook was found to be very good with mean per cent score 93.12. The component wise comprehension in all ten components i.e. concept of menstruation, menstrual cycle, managing menstruation, products used during menstruation, benefits of Sanitary Napkins, availability of vending machine in schools and colleges, hygiene during menstruation, disposal of sanitary napkins, coping with stress and discomfort during menstruation and precautions during menstruation mean per cent scores ranged between 72-100. Thus, it could be concluded that the comprehension of flipbook was found to be good and the developed flipbook can be utilized by the various government, non-government and welfare organizations to generate awareness about the hygiene during menstruation among rural and tribal women.

\section{Introduction}

Menstruation is a normal physiological process indicating beginning of reproductive life but sometimes it is considered as unclean phenomenon in the Indian society. The issue of menstrual hygiene is inadequately acknowledged and has not received proper attention. Good hygienic practices, such as use of sanitary pads and adequate washing of the genital areas, are essential during menstruation period. Women and girls of reproductive age need access to clean and soft absorbent sanitary products which in the long run protect their health from various infections. To this effect, the practice of good menstrual hygiene reduces the incidence of reproductive tract infection (RTI).Every year approximately $10 \%$ of women worldwide are exposed to genital infections including urinary tract infections and bacterial vaginosis, and $75 \%$ of women have a history of a genital infection. Specifically, the common risk factors for vaginal infections include pregnancy and poor hygiene. The women/girls should be educated about significance of menstruation and 
development of secondary sexual characteristics, selection of sanitary menstrual absorbent and its proper disposal. In such conditions there is dearth of appropriate aid especially in the field of hygiene during menstruation with the specific features suited to the requirements and understanding level of the rural women which can be used as a ready reference by the functionaries of different organizations. Therefore, the present study was planned to field test flipbook for its comprehension by rural women.

\section{Materials and Methods}

The study was conducted in randomly selected Girwapanchayatsamiti of Udaipur district of Rajasthan state. A sample of 50 rural women was taken from randomly selected one village i.e. Kanpur of Girwapanchayatsamiti. One group post-test only design was used in which the respondents were exposed to the flipbook and immediately after exposure post test was conducted to know comprehension of the messages by the respondents. For collection of data personal interview technique was used.

\section{Results and Discussion}

\section{Background information of the respondents}

More than 40 per cent respondents were in the age group of 20-28 years, 30 per cent were in the age group of 29-37 and 25 per cent were of 38-45 years. Majority of the respondents $(85 \%)$ belonged to other backward caste, 11 per cent respondents were from schedule tribe and rest of them (4\%) belonged to general category. Majority of the respondents $(91 \%)$ were married and only 9 per cent were unmarried. More than40 per cent of the respondents were illiterate, 19 per cent of the respondents were educated upto high school, graduate and above (18\%), upto middle school $(10 \%)$ and rest of the respondents were educated primary upto school and can read and write. Majority of the respondents $(80 \%)$ had farming as their main family occupation. However, majority $(67 \%)$ of the respondents had no subsidiary occupation while 33 per cent respondents had one subsidiary occupation. Similarly 20 per cent respondents were working as farm labourers. More than half of the respondents belonged to medium size family (5 to 8 members), 44 per cent respondents had small size family $(51.67 \%)$ and only 1 per cent of the respondents had large family size consisting of more than 8 members.

\section{Comprehension of messages through flipbook by rural women}

The designed flipbook was field tested with clientele i.e. rural women for its comprehension so that necessary modification could be made accordingly. The flipbook contained fifteen flipcharts and focused on important messages related to hygiene during menstruation. The visuals are selected simple, bold and clear. The respondents were exposed to developed flipbook with an instructional approach by the investigator. In this, each flip chart of the flipbook was explained to them covering every visual and message in it. Then 15 minutes were given to recapitulate whatever the respondents understood from the flipbook. After this, each group of the rural women was again exposed to the entire flipbook without instructions. Immediately after exposure, information about comprehension of messages for each component of hygiene during menstruation was collected with the help of developed tool.

\section{Overall comprehension}

Data presented in Table 1 reveal that the overall comprehension of messages through flipbook was very good with mean per cent score 93.12. Similarly in all the components of hygiene during menstruation the 
comprehension was found to be very good. Maximum scores were observed in the component 'products used during menstruation, benefits of sanitary napkin, ways to dispose the sanitary napkin, nutrition during menstruation and precautions during menstruation' (100MPS) and 'Coping stress and discomfort during menstruation' (96MPS) followed by 'hygiene during menstruation (95.33MPS)' and 'Problems during menstruation (94MPS). Lowest comprehension was observed in the component 'availability of vending machine (84MPS)', 'concept of menstruation (83MPS)' and 'managing menstruation (72 MPS). The reason for this might be most of respondents were illiterate and no knowledge about process of menstruation and availability of vending machine in schools and colleges.

Rathoreet al., (2005) inferred that the overall comprehension of key massages in the folder was excellent as messages related to what is poshak-supplementary ingredients of poshak, how to prepare poshak, method for preparation of poshak were comprehended by almost all the respondents while how much poshak to be given to the child, introduction and advantages of poshak were comprehended by $92.5-95$ per cent respondents.
The results are in line with the findings of Sharma (2009) who conducted a study on "Designing and field testing of instructional material of entrepreneurship development for rural women", and revealed that the overall comprehension of multimedia CD was found to be 95.6 per cent. The component wise comprehension in all nine components i.e. concept of entrepreneurship development, benefits of entrepreneurship development, traits of entrepreneur, realization of opportunity, obtaining training, consolidation of resources, starting production, marketing of the product and expansion of the unit mean percent scores ranged between 89.4-99.8. Overall comprehension of flip book was found to be very good with mean percent score 94.9.

A study by Jain (2017) on "Development and field-testing of a flipbook on 'vegetables in diet' for rural women", revealed that the developed flipbook was rated in between good to excellent category by experts and the visual perception and comprehension of flip book by respondents were rated as very good and excellent, respectively. Thus, it could be concluded that the developed flipbook on 'Vegetables in diet' was excellent.

Table.1 Overall comprehension of messages through flipbook by the respondents

\begin{tabular}{|l|c|}
\hline \multicolumn{1}{|c|}{ Components } & Mean Percent Score \\
\hline Concept of menstruation & 83 \\
\hline Managing menstruation & 72 \\
\hline Products used during menstruation & 100 \\
\hline Benefits of sanitary napkin & 100 \\
\hline Availability of vending machine & 84 \\
\hline Hygiene during menstruation & 95.33 \\
\hline Ways of disposal of sanitary napkin & 100 \\
\hline Problems during menstruation & 94 \\
\hline Coping with stress and discomfort during menstruation & 96 \\
\hline Nutrition during menstruation & 100 \\
\hline Precautions during menstruation & 100 \\
\hline \multicolumn{1}{|c|}{ Overall comprehension } & 93.12 \\
\hline
\end{tabular}


Table.2 Component wise comprehension of messages through flipbook by the respondents

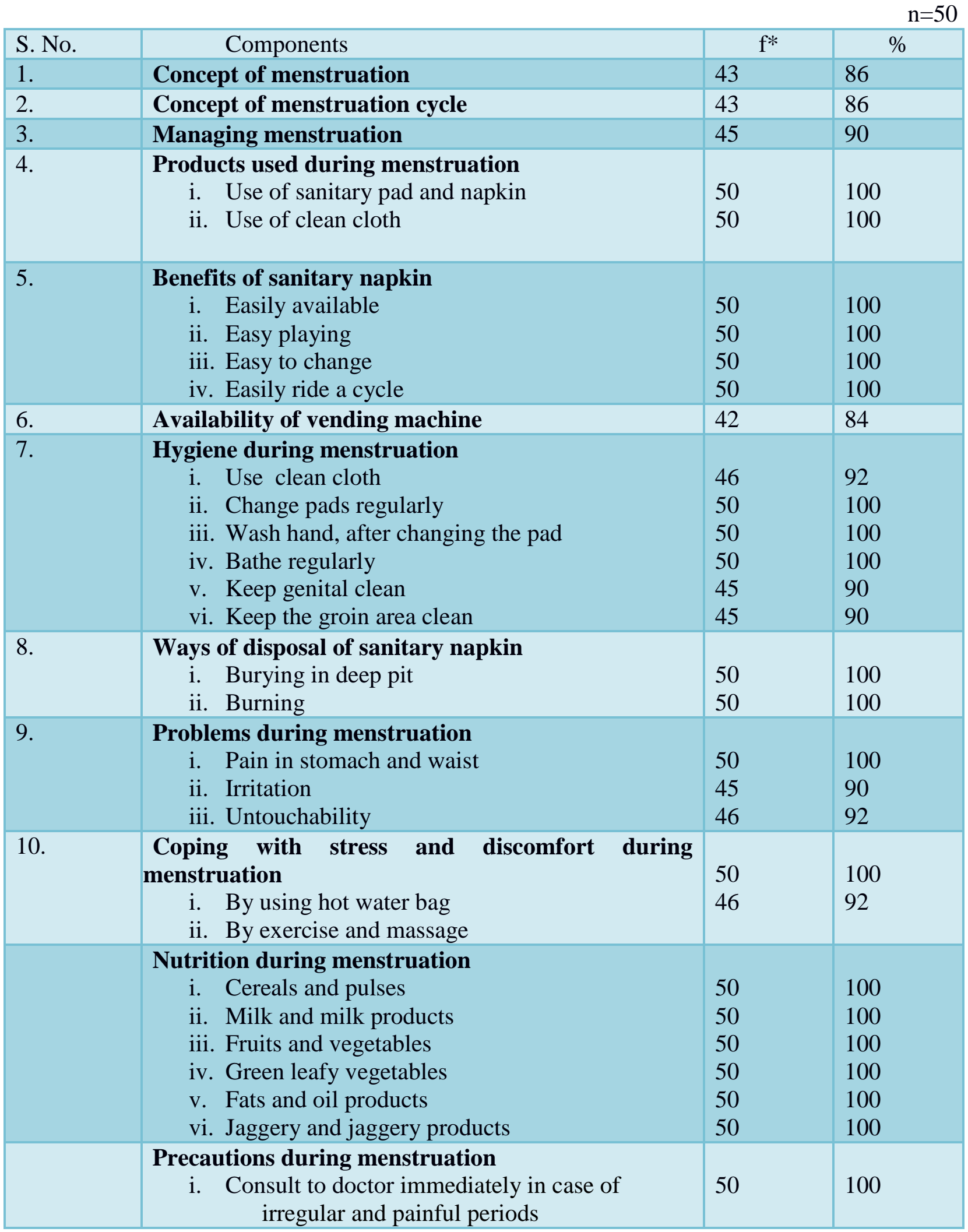

*= Multiple response 


\section{Components wise comprehension}

Perusal of Table 2 indicates that messages related to products used during menstruation, benefits of sanitary napkin, nutrition during menstruation, disposal of sanitary napkin and to precautions during menstruation were comprehended by cent percent respondents. Whereas 100 per cent respondents got the key message on 'Pain in stomach and waist' followed by 90-92 per cent of the respondents were able to comprehend the messages on 'untouchability' and 'irritation'. Majority of the respondents $(92-100 \%)$ successfully comprehended the messages related to coping with stress and discomfort during menstruation i.e. by using hot water bag and by exercise and massage. Table further shows that messages related to hygiene during menstruation i.e. use clean cloth, change pads regularly, wash hand after changing the pad, bathe regularly, keep groin area clean and keep the groin area dry was very good as all the respondents (90-100\%) comprehended all the messages correctly. However, with regard to message related to managing menstruation, 90 per cent respondents were comprehended. Whereas two messages related to concept of menstruation and menstruation cycle was comprehended by 86 per cent respondents and 84 per cent respondents got the key message on 'availability of vending machine in school and college' correctly.

Dudi and Singh (2008) reported that all the respondent had medium knowledge in all aspects of health and nutrition, after the exposure of flash card, flipbook and chart post test was conducted and found that respondents $(60 \%)$ were in the category of medium knowledge with mean per cent score of 79.7 and 26 per cent respondents were in low knowledge category with mean per cent score of 57.3 while 14 per cent respondents were in high knowledge category in aspect of basics of foods and nutrition. Rowe and Llic
(2009) in a pilot survey on author attitudes and experiences about posters, reported that overall 62 per cent of participants agreed, or strongly agreed, with the statement that posters are a good medium for knowledge transfer in the teaching learning environment. The majority of participants believed that the visual aspect of an academic poster was more appealing to viewers then the text and subject content. Almost all of the participants (94\%) believed that the imagery and composition of the poster (e.g. colours, figures) was the main factor in catching the viewer's attention.

Study by Rathore and Trikha (2009) revealed that use of simple language was reported by 89.45 per cent by the readers of Apna Patrawhere as 75.39 per cent readers reported less use of illustrations followed by appropriate number of technical words (66.80\%), appropriate size of printing $(85.15 \%)$, fair quality of printing $(76.56 \%)$, attractive cover page $(53.12 \%)$, less useful information $(55.08 \%)$, interesting level of presentation $(44.14 \%)$, less number of pages $(69.14 \%)$ and up-to date information $(53.94 \%)$.

Patil and Kadam (2013) reported that majority of the readers $(85.89 \%)$ of Shetkari farm magazine reported that number of illustrations appeared in Shetkari farm magazine were sufficient in number. 86.66 per cent readers reported that understanding of illustrations provided for explanation were easy to understand. Majority of the respondents $(88.34 \%)$ readers perceived that quality of illustrations were very good. About the usefulness of illustrations provided for explanations were perceived as very useful by more than half $(52.50 \%)$ readers of Shetkari farm magazine.

Thus, it could be concluded that the comprehension of flipbook was found to be good and the developed flipbook can be 
utilized by the various government, nongovernment and welfare organizations to generate awareness about the hygiene during menstruation among rural and tribal women.

\section{References}

Dudi, A. and Singh, A.R. 2008. Effectiveness of developed training package on health and nutrition for rural women. Rajasthan Journal of Extension Education.(16): 114-118.

Jain, S. 2017. Development and field-testing of a flipbook on vegetables in diet for rural women. Journal of Community Mobilization and Sustainable Development. 12(1): 136-140.

Patil, S.D. and Kadam, L.R. 2014. Study of usefulness and critical analysis of illustrations appeared in Shetkari farm magazine. Indian Journal of Extension Education and Rural Development. (22): 200-202.

Rathore, R., Singh, A. and Arora, R. 2005. Comprehension of folder on poshak supplementary food. Journal of Extension Education.(6):70-72.

Rathore, R. and Trikha, N.R. 2009.Improving livelihood security of farmers through farm publications. Rajasthan Journal of Extension Education.(16):37-39.

Rowe, N. and Llic, D. 2009. What impact do posters have on academic knowledge transfer? Journal of BMC Medical Education. Cited from https://bmcmededuc.biomedcentral.co $\mathrm{m} / \mathrm{arti}$

cles/10.1186/1472-6920-9-71 retrieved on $12 / 7 / 2017$.

\section{How to cite this article:}

Seema Dangi and Vishakha Bansal. 2018. Field Testing of Flipbook on Hygiene During Menstruation for its Comprehension by Rural Women. Int.J.Curr.Microbiol.App.Sci. 7(07): 982-987. doi: https://doi.org/10.20546/ijcmas.2018.707.119 